\title{
A High-Frequency Surface Wave Radar Simulation Using FMCW Technique for Ship Detection
}

\author{
Ahmad Nugroho Jati ${ }^{1}$, Ahmad Fauzi Haqqoni ${ }^{1}$, Iswandi ${ }^{1}$, Risanuri Hidayat ${ }^{1}$
}

\begin{abstract}
Indonesia is an archipelagic country with a vast sea area. This vast sea area becomes a challenge in conducting regional surveillance to maintain maritime conditions. The use of buoys and satellites still has shortcomings in carrying out surveillance despite its excellent surveillance capabilities. A highfrequency radar technology with 3-30 MHz frequency and surface wave propagation are very suitable because it has a radar range that can cross the horizon or commonly refer to as Over the Horizon (OTH). The Frequency Modulated Continuous Wave (FMCW) technique on this radar obtains distance and velocity information by a continuously transmitted frequency modulation. The use of radar in Indonesia for marine surveillance is still infrequent. Therefore, it is relatively difficult to conduct testing and obtain data. In addition, the direct examination requires extended time, so a simulation program is needed. This paper discusses the design of a High-Frequency Surface Wave Radar (HFSWR) simulation program using FMCW modulation technique. The simulation program detected two objects based on time delays due to the distance and velocity of the object with a maximum range of $350 \mathrm{~km}$. It displayed the results in an informative manner. The object detection was based on the results of the Fast Fourier Transform (FFT) from the mixed signals. The mixed signal is a combination of transmitted signal and reflected signal in which there are time delay components due to the object. The simulation program had been tested with input values of distance and velocity that vary, both for one object and two objects, in the radial direction. It generated output that was close to the input value with a level of accuracy of $\pm 2 \mathrm{~km}$.
\end{abstract}

Keywords - Fast Fourier Transform, FMCW, Doppler Frequency, HFSWR, Radar.

\section{INTRODUCTION}

Indonesia is an archipelagic country with an extensive area, namely, the land area of $1,904,569 \mathrm{~km}^{2}$, a water area of $6,315,222 \mathrm{~km}^{2}$, and a coastline length of $108,000 \mathrm{~km}$ [1]. Radar has a significant role in Indonesia with such a large area to maintain the security.

The HF radar technology is frequently used in the fields of oceanography or ocean monitoring with extensive water conditions and lengthy coastlines [2]. A radar using a surface wave propagation type is also called a High-Frequency Surface Wave Radar (HFSWR) [3]. The HFSWR is very suitable for ocean monitoring because with a frequency of 3-30 MHz, the radar range can cross the horizon, or it is commonly called as Over the Horizon (OTH) [4]. The HFSWR is one of the other

\footnotetext{
${ }^{1}$ Department of Electrical and Information Engineering Universitas Gadjah Mada, Jl. Grafika No. 2, Bulaksumur, Yogyakarta 55281 INDONESIA (telp: 0274-552305; fax: 0274552305; e-mail: ahmad.nugroho.j@mail.ugm.ac.id, ahmad.fauzi.h@mail.ugm.ac.id, iswandi@ugm.ac.id, risanuri@ugm.ac.id)
}

radar replacement innovations that has several shortcomings. One of them is the Automatic Identification System (AIS) that can be manually turned off by shipowners. Another weakness is the Synthetic Aperture Radar (SAR) that cannot be updated at any time because it depends on the satellites, aircraft or Unmanned Aerial Vehicle (UAV) that pass through that area [5]-[7].

The HFSWR uses an FMCW modulation technique, which is a radar modulation technique that can obtain distance information using a continuously transmitted frequency modulation [8]. In general, the Frequency Modulated Continuous Wave (FMCW) radar technology requires a very low transmit power compared to other radar types [9], [10]. Some of these advantages made the FMCW radar selected from several different modulation types, such as pulse radar, Frequency Modulated Interrupted Continuous Wave (FMICW), and multi-frequency continuous wave [11], [12].

Radar is a complex system with empirical data covering many parameters and natural factors, as well as direct observations that take a long time. Therefore, simulation is needed to observe how the radar detects a target and obtains information about distance and velocity as well as displays information in an informative manner.

This paper aims to create an HFSWR simulation program with FMCW as the modulation technique to detect ship which has a certain velocity and distance from the radar source. The target ships used are considered to have the same shape. The influence of ocean waves, noise, and clutter are not considered in simulation because more research still to be done to see the effects on reflected waves of objects. The detection results of the simulation program were displayed in the form of a rangevelocity map showing the distance and velocity of each object. The object movements are displayed with animation to see the radial motion of an object.

\section{High-Frequency SuRface WAVE RADAR}

A High Frequency Radar (HFR) is radio equipment that transmits electromagnetic waves in high-frequency bands between 3-30 MHz, with the wavelengths ranging from $10 \mathrm{~m}$ to $100 \mathrm{~m}$, with a radar range as far as $350 \mathrm{~km} \mathrm{[13].}$

Two HFR types are divided based on how the radio waves propagate, namely, HFR with wave propagation in the sky (skywave) and HFR with a wave propagation on the surface (surface wave). Skywaves propagate through the ionosphere reflection and detect targets on the horizon. This technique is mainly used for remote tracking, but it has spatial resolution limitations. This section focuses on discussing surface waves or commonly called HFSWR, which are used for sea-level observations. The basic principle of this technique is to utilize the wave reflection energy (backscatter) from the seawater 


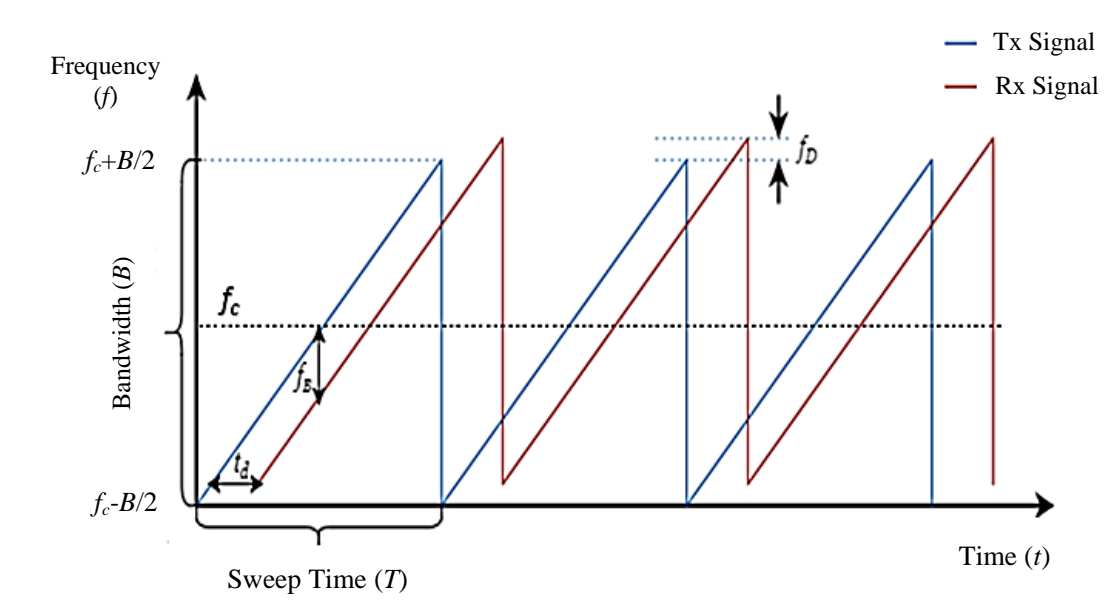

Fig. 1 The FMCW signal model.

surface emitted by the transmitter station, thus allowing the energy spectrum to be received back at the receiving station. The processes utilize the resonance of these waves, well known as the Bragg scattering. The received information is in the form of waves, wind, and other components. The HFSWR monostatic reception power from the target reflection can be written as in (1).

$$
P_{r}=\frac{P_{t} G_{t} G_{r} \sigma A^{4} \lambda^{2}}{(4 \pi)^{3} R^{4} L_{s}}
$$

where $P_{r}$ is the received peak power, $P_{t}$ is the transmitted peak power, $G_{t}$ is the transmitting antenna gain, $G_{r}$ is the receiving antenna gain, $\sigma$ is the target's Radar Cross Section (RCS), $\lambda$ is the wavelength, $R$ is the target distance, $L_{s}$ is the system loss, and $A$ is the Norton surface wave attenuation factor at the distance of $R(A<1)$ [14]. Environmental HFSWR noise is more dominant thermal noise.

\section{FREQUENCY Modulated ContinuOUS WAVE (FMCW)}

FMCW is one of radar methods using linear and continuous frequency modulation (Continuous Wave, $\mathrm{CW}$ ). In contrast to simple CW radars, FMCW radars can adjust the value of the transmitting signal frequency during measurement. FMCW utilizes beat frequencies to obtain the distance of objects to the radar. Modulating signals are generally in the form of triangular, sawtooth, or sinusoidal waves [15]. Fig. 1 shows the FMCW signal model [16].

Signals in the FMCW method are transmitted by periodically increase or decrease the frequency. When the reflected signal is received, the change in frequency is delayed by $\tau$.

FMCW radar has many advantages compared to other radar types, including being able to simultaneously measure the distance and relative velocity of objects and function well in various kinds of weather and atmospheric conditions [17].

\section{A. The Working Principle of FMCW}

The transmitted frequency increases linearly as a time function during sweep time $(T)$. Transmission duration is defined as $t$. Working frequency $\left(f_{c}\right)$ is the frequency utilized by the radar during operation and will change depending on the utilized bandwidth $(B)$. The FMCW signal model over the sweep time range can also be referred to as chirp. The transmitted chirp signal can be written in (2).

$$
x_{t x}(t)=A_{t x} \cos \left(2 \pi f_{c} t+\alpha t^{2}\right)
$$

where $A_{t x}$ is the transmitted chirp amplitude, and $\alpha$ is the chirp rate. Chirp rate can be defined with (3).

$$
\alpha=\frac{B}{T} \text {. }
$$

Chirp rate shows the change rate velocity from the FMCW signal that affects object detection. The frequency value at each $t$ time in the sawtooth modulation model can be defined with (4).

$$
f(t)=f_{c}+\frac{B}{T} t=f_{c}+\alpha t .
$$

The previous equation only describes the duration of the first chirp, Therefore, modifications must be made to describe the transmission signal with $n$ sweep by considering $t_{s}$ as the time of the first sweep of the $n$ sweep and defined by (5).

$$
t=n T+t_{s} ; \quad \text { for } 0<t_{s}<T .
$$

The FMCW radar transmits continuous waves with increasing frequency. The transmitted wave will be reflected by an object and then received by the receiver. The reflected signal from the object has the same form, but it has a time delay $\tau$, which can be defined in (6).

$$
\tau=\frac{2(R+v t)}{c}=\frac{2\left(R+v\left(n T+t_{s}\right)\right)}{c} .
$$

The time delay on the reflected signal contains information on $R$ distance and the radial speed $v$ of the object. The reflected signal is then received by the antenna with an additional time delay so that the received signal equation becomes as in (7).

$$
x_{r x}(t)=A_{r x} x_{t x}(t-\tau) .
$$

Correspond to the FMCW radar principle, the transmitted signal is then multiplied by the received signal, which generates (8).

$$
x_{m}(t)=x_{t x}(t) x_{r x}(t)
$$




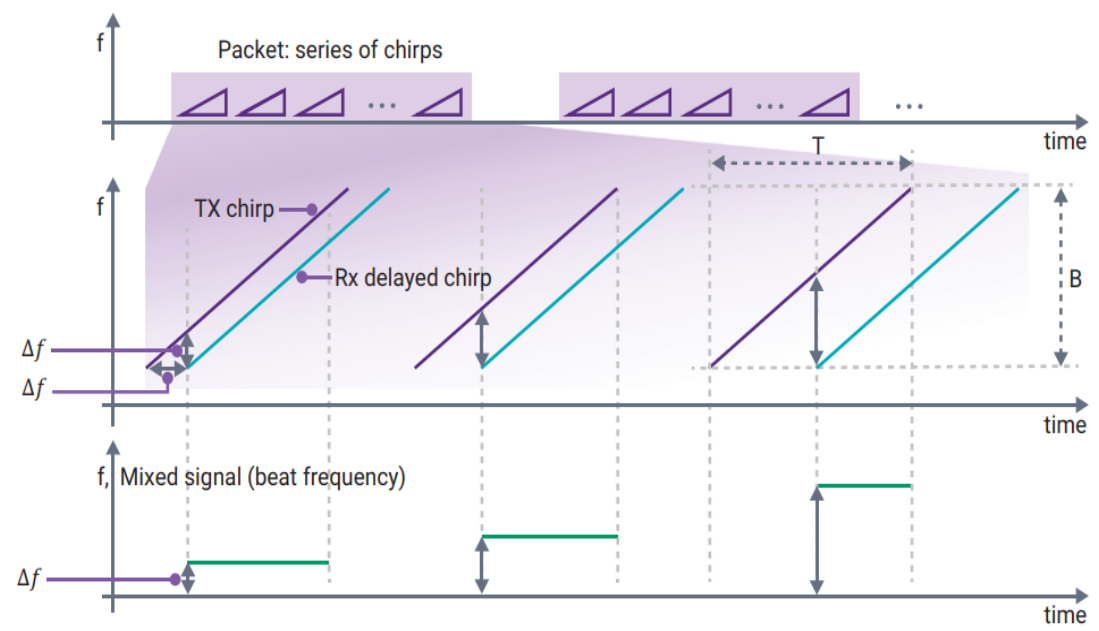

Fig. 2 The FMCW transmitting and receiving signals.

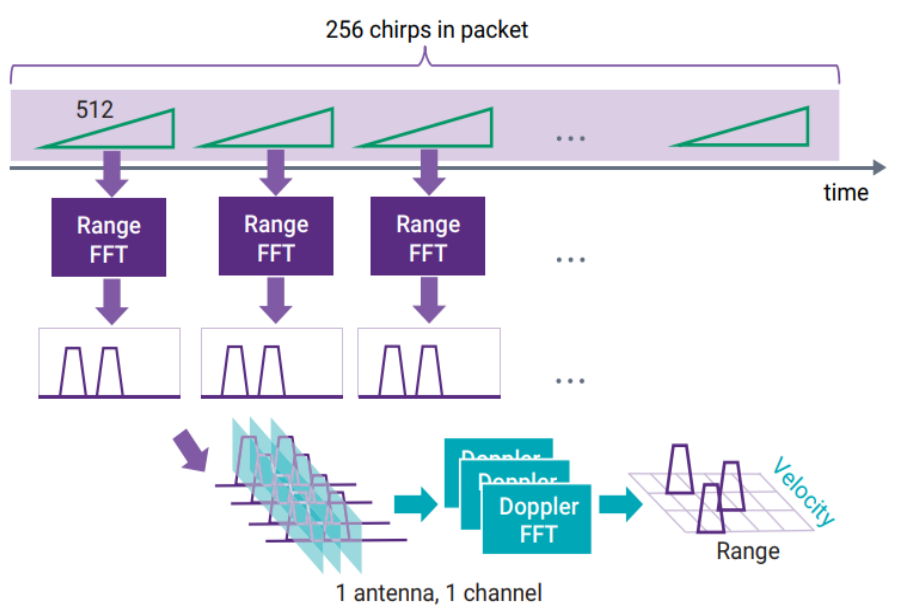

Fig. 3 An illustration of FFT 2D process.

With an equation simplification, the received mixed wave equation is obtained as in (9).

$$
x_{m}=\frac{A_{t x} A_{r x}}{2} \cos \left(2 \pi\left(f_{c} \tau+\alpha \tau t_{s}-\frac{\alpha \tau^{2}}{2}\right)\right) \text {. }
$$

\section{B. Fast Fourier Transform (FFT)}

Radar with the FMCW modulation technique allows us to simultaneously obtain distance and velocity by performing Fast Fourier Transform (FFT) operations. FFT transforms the signal from the time domain to the frequency domain. The first FFT is carried out on a single chirp in which there are several samples. From the first FFT, the beat frequency $\left(f_{b}\right)$ was obtained. It showed the distance value of the object. With propagation velocity $(c)$, the distance of $R$ objects can be determined using (10).

$$
R=\frac{f_{b} c}{2 \alpha}
$$

The distance resolution $(\Delta R)$ of two objects can be determined using (11).

$$
\Delta R=\frac{c}{2 B}
$$

Fig. 2 is an illustration of the FMCW transmitting and receiving signals [18]. After conducting FFT in all chirps, the following step to obtain velocity value is to do the second FFT. The first FFT generates a phase related to beat frequency that changes linearly with chirp number. Phase change shows how the signal frequency changes over the simulation period. This change is based on Doppler frequency shift $\left(f_{d}\right)$, which is a frequency shift that arises due to the relative motion of the object to the radar. The Doppler frequency $f_{d}$ is used to find the object velocity value $\left(v^{\prime}\right)$. An illustration of the administered FFT process is shown in Fig. 3. The Doppler frequency is used to obtain the object velocity, as in (12).

$$
v=\frac{f_{d} c}{2 f_{c}}
$$

\section{METHODOLOGY}

The article flowchart is shown in Fig. 4. This general system design provides a preliminary overview of the research flow details as well as the problem limitations of this paper.

The research flow started from a literary study on relevant topics that had similarities with the topic discussed in this 


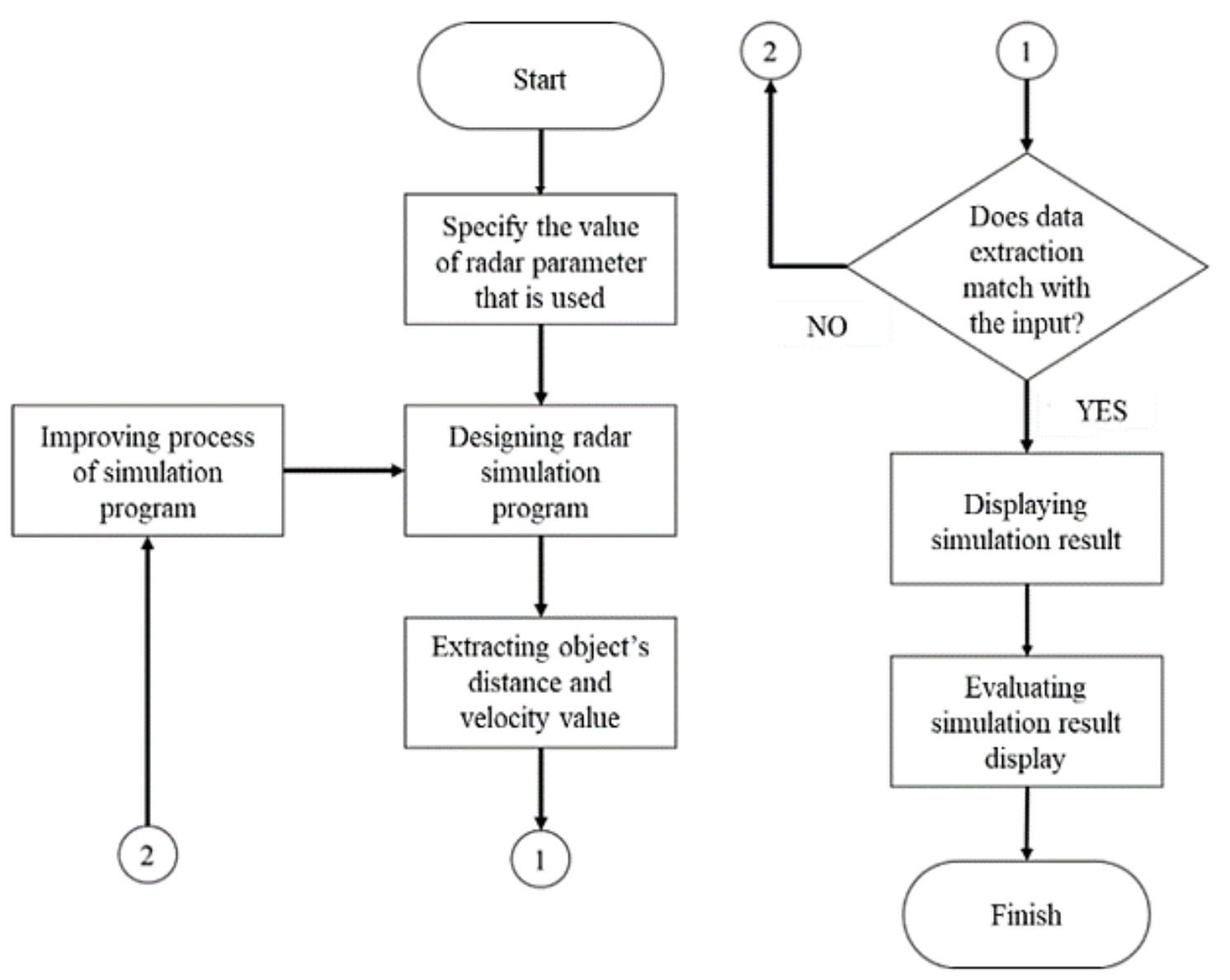

Fig. 4 Research flowchart.

TABLE I

THE UTILIZED RADAR PARAMETERS

\begin{tabular}{|l|c|}
\hline \multicolumn{1}{|c|}{ Parameters } & Value \\
\hline Carrier frequency $\left(f_{c}\right)$ & $8 \mathrm{MHz}$ \\
\hline Bandwidth $(B W)$ & $125 \mathrm{kHz}$ \\
\hline Total time $(T)$ & $66.56 \mathrm{~s}$ \\
\hline Sweep time $(S t)$ & $0.26 \mathrm{~s}$ \\
\hline Number of chirps $(D)$ & 256 \\
\hline Number of samples per chirp $(N)$ & 1,024 \\
\hline Maximum distance $\left(R \_\right.$max $)$ & $350 \mathrm{~km}$ \\
\hline Propagation velocity $(c)$ & $3 \times 10^{8} \mathrm{~m} / \mathrm{s}$ \\
\hline
\end{tabular}

paper. The next step was to set the parameter values of the simulated radar. There were various initial parameter values needed in this study. Table I explains the utilized parameters.

The duration of the simulation starts from $t=0 \mathrm{~s}$ to $t=66.56$ $\mathrm{s}$ obtained from the multiplication between the duration of the chirp and the number of chirps. The number of chirps and the number of samples per chirp are power of two that formed a range-doppler map. The required distance resolution is $1.2 \mathrm{~km}$ resulting in bandwidth of $125 \mathrm{kHz}$.

The design of program simulation using the FFT was carried out after setting the parameters. The FFT results were extracted to obtain the object's distance and velocity values. The results of the simulation program were displayed in a range-velocity map and object motion animation.
TABLE II

TEST RESUlts OF DistANCE AND VELOCITY INPUTS

\begin{tabular}{|c|c|c|c|c|}
\hline \multirow{2}{*}{ Test } & \multicolumn{4}{|c|}{ Input } \\
\cline { 2 - 5 } & $\boldsymbol{R}_{\mathbf{1}} \mathbf{( k m )}$ & $\boldsymbol{V}_{\mathbf{1}}(\mathbf{m} / \mathbf{s})$ & $\boldsymbol{R}_{\mathbf{2}}(\mathbf{k m})$ & $\boldsymbol{V}_{\mathbf{2}} \mathbf{( m / s )}$ \\
\hline 1 & 180 & 20 & 70 & 12 \\
\hline 2 & 50 & 12 & 70 & 15 \\
\hline 3 & 150 & 8 & 170 & 5 \\
\hline 4 & 120 & 3 & 30 & 20 \\
\hline 5 & 178 & 12.5 & 67 & 18.8 \\
\hline
\end{tabular}

\section{RESUlTS AND DisCUSSIONS}

\section{A. Simulation Program Design}

The results of simulation program design were tested with five times experiments by inputting distance and velocity of the two different objects. Table II shows the values of object distance and velocity.

The test results are shown in Table III. The results show that distance has an error with a level of accuracy of $\pm 2 \mathrm{~km}$ using equation (11). The accuracy level depends on sample numbers per chirp. The more sampling number, the better level of accuracy, but computation becomes heavier.

\section{B. Visualisation of the Simulation Program}

The radar simulation program utilized an object with the first object's velocity of $20 \mathrm{~m} / \mathrm{s}$ and a distance of $200 \mathrm{~km}$. If the 


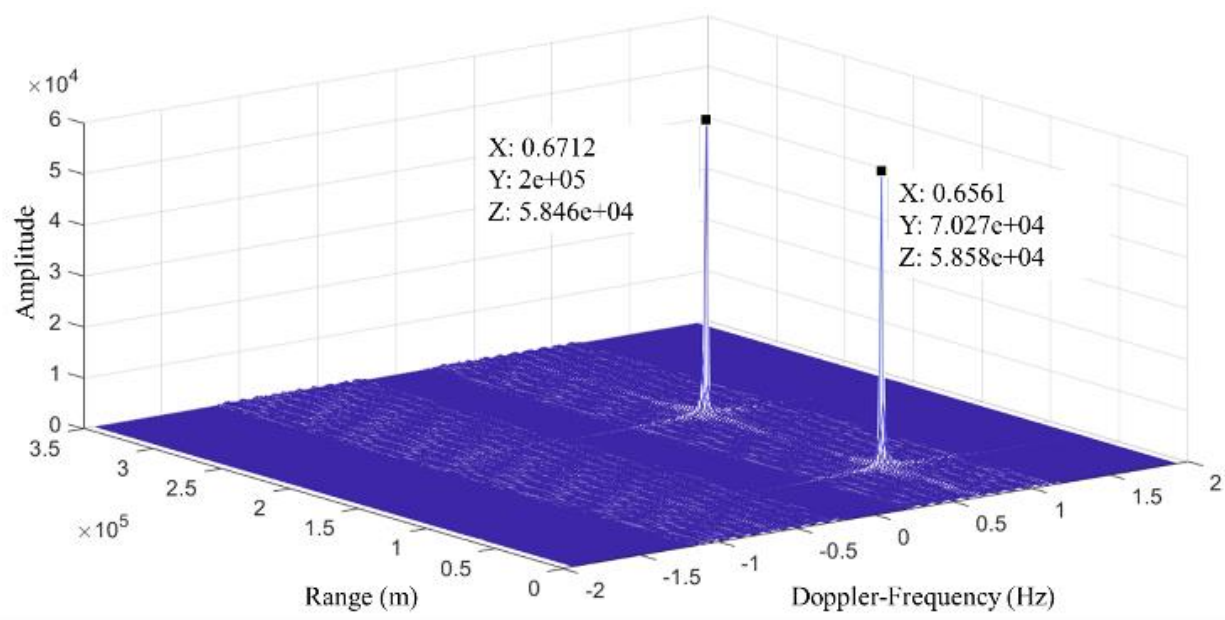

Fig. 5 Range-Doppler map of two objects.

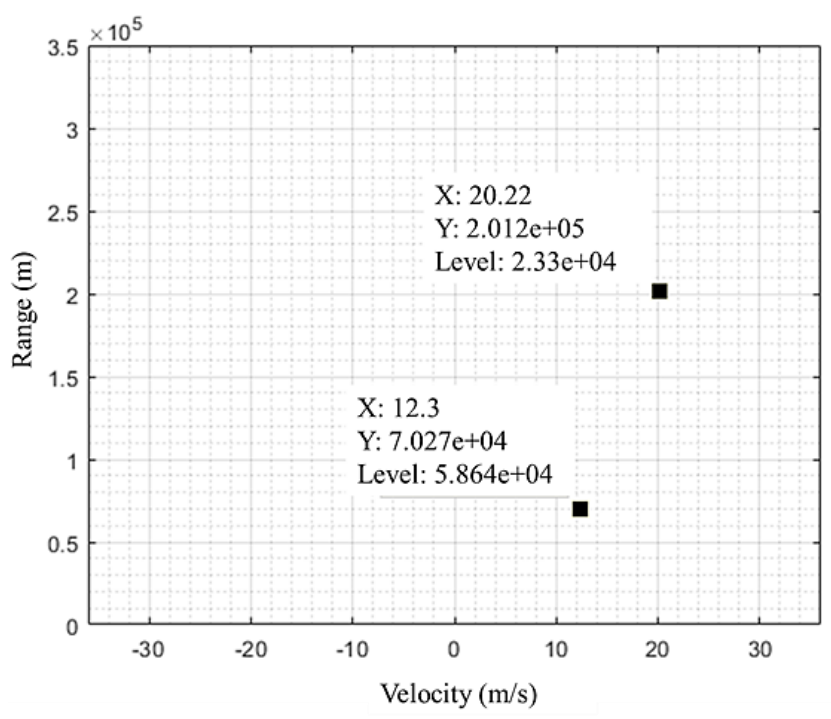

Fig. 6 Range-velocity map of two objects.

TABLE III

TEST RESUlts OF SimUlation PROGRAMS

\begin{tabular}{|c|c|c|c|c|}
\hline \multirow{2}{*}{ Test } & \multicolumn{4}{|c|}{ Output } \\
\cline { 2 - 5 } & $\boldsymbol{R}_{\mathbf{1}} \mathbf{( k m )}$ & $\boldsymbol{V}_{\mathbf{1}}(\mathbf{m} / \mathbf{s})$ & $\boldsymbol{R}_{\mathbf{2}} \mathbf{( k m )}$ & $\boldsymbol{V}_{\mathbf{2}} \mathbf{( m / \mathbf { s } )}$ \\
\hline 1 & 180 & 20.5 & 70.2 & 12.3 \\
\hline 2 & 49.8 & 12 & 70.3 & 15.4 \\
\hline 3 & 150.7 & 8.3 & 169.9 & 4.9 \\
\hline 4 & 31.8 & 3 & 119.5 & 20.5 \\
\hline 5 & 178.4 & 12 & 69 & 18.2 \\
\hline
\end{tabular}

simulation program uses two objects, the second object is added with a velocity of $12 \mathrm{~m} / \mathrm{s}$ and a distance of $70 \mathrm{~km}$.

Fig. 5 shows a range-Doppler map or can be called a contour map. The $x$-axis is the object's Doppler frequency obtained from the second FFT calculation. Whereas the $y$-axis is the axis of object distance derived from the beat frequency from the first FFT.

Fig. 6 is a simulation result using two objects displayed on the range-velocity map. The distance and velocity values of the two objects used in the first test generated two objects that could be detected by the simulation. A negative value on the velocity axis indicates that the object is moving outward from the radar, and a positive value indicates the object is moving inward to the radar.

\section{Result of Object Motion Animation Visualization}

For animation visualization, objects were randomly positioned and made to move every 10 minutes toward radar in the simulation program, so that objects appeared to move in animation. In Fig. 7, the first object is indicated by a blue 'o' symbol, and the second object is indicated by a red 'o' symbol.

Table IV presents the detected object's location in more detail. It can be seen that for object 1 , the absolute distance between locations is around $12 \mathrm{~km}$, obtained from calculations intended for finding the second location.

\section{CONCLUSIONS}

The research result on the HFSWR simulation program with the FMCW technique to detect ships is a simulation program 


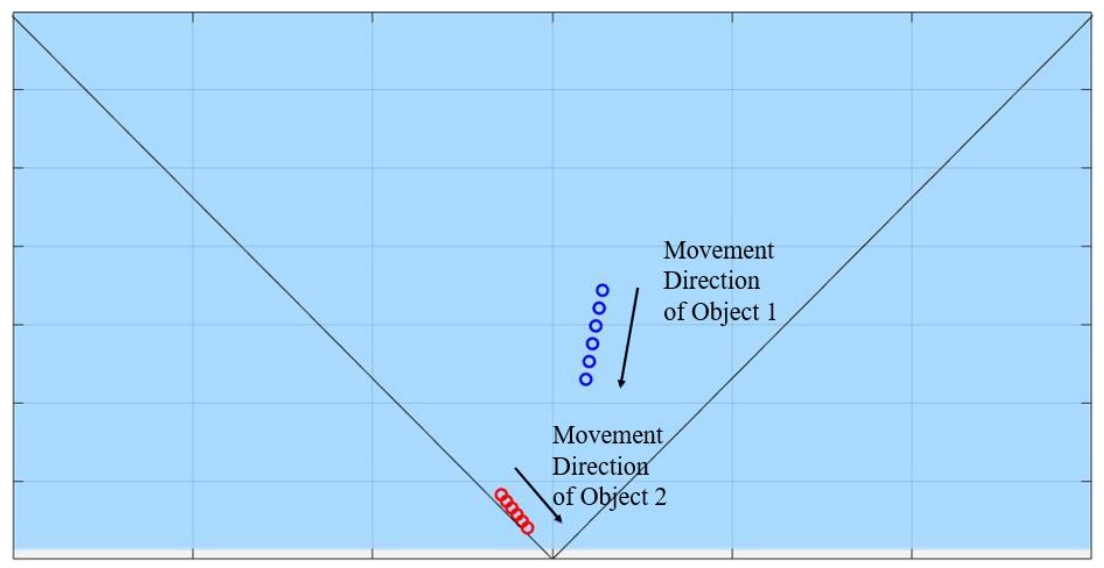

Fig. 7 One-way motion animation view of radar.

TABLE IV

OBJECT LOCATION VALUE

\begin{tabular}{|l|l|c|c|c|}
\hline \multicolumn{2}{|c|}{ Object/Point } & $\boldsymbol{x}$-Axis & $\boldsymbol{y}$-Axis & $\begin{array}{c}\text { Radial } \\
\text { Distance } \\
(\mathbf{k m})\end{array}$ \\
\hline \multirow{4}{*}{\begin{tabular}{l} 
Object \\
\cline { 2 - 5 }
\end{tabular}} & Location 1 & $5.5863 \times 10^{4}$ & $1.7193 \times 10^{5}$ & 180.780 \\
\cline { 2 - 5 } & Location 2 & $5.2166 \times 10^{4}$ & $1.6055 \times 10^{5}$ & 168.810 \\
\cline { 2 - 5 } & Location 3 & $4.8470 \times 10^{4}$ & $1.4917 \times 10^{5}$ & 156.850 \\
\cline { 2 - 5 } & Location 4 & $4.4773 \times 10^{4}$ & $1.3780 \times 10^{5}$ & 144.890 \\
\cline { 2 - 5 } & Location 5 & $4.1076 \times 10^{4}$ & $1.2642 \times 10^{5}$ & 132.930 \\
\cline { 2 - 5 } & Location 6 & $3.7380 \times 10^{4}$ & $1.1504 \times 10^{5}$ & 120.960 \\
\hline \multirow{4}{*}{\begin{tabular}{l} 
Object \\
\cline { 2 - 5 }
\end{tabular}} & Location 1 & $-5.6849 \times 10^{4}$ & $4.1303 \times 10^{4}$ & 70.269 \\
\cline { 2 - 5 } & Location 2 & $-5.1014 \times 10^{4}$ & $3.7064 \times 10^{4}$ & 63.057 \\
\cline { 2 - 5 } & Location 3 & $-4.5180 \times 10^{4}$ & $3.2825 \times 10^{4}$ & 55.846 \\
\cline { 2 - 5 } & Location 4 & $-3.9346 \times 10^{4}$ & $2.8586 \times 10^{4}$ & 48.634 \\
\cline { 2 - 5 } & Location 5 & $-3.3511 \times 10^{4}$ & $2.4348 \times 10^{4}$ & 41.422 \\
\cline { 2 - 5 } & Location 6 & $-2.7677 \times 10^{4}$ & $2.0109 \times 10^{4}$ & 34.211 \\
\hline
\end{tabular}

that can recognize objects with experiments using one object or two objects. The maximum distance for the simulation program is $350 \mathrm{~km}$, with a degree of accuracy of $\pm 2 \mathrm{~km}$. A visualization of program simulation with range-velocity map and object motion animation can be displayed with the object radial motion, either approaching or distancing. The range-Doppler map display provides information about the Doppler frequency, which shows the velocity value at the distance value with an object within. The detected object's direction is the radial object's direction towards the direction of radar's view, that is, distancing from or approaching the radar. It is because the configuration utilized in this HSWR simulation program uses only one receiving antenna. The radar display visualization result was made by taking the object's location every 10 minutes and carried out six times.

\section{REFERENCES}

[1] (2018) "Rujukan Nasional Data Kewilayahan: Luas NKRI 8,3 Juta Kilometer Persegi,” [Online], http://www.big.go.id, access date: 2-Dec2018.

[2] A. Dzvonkovskaya, K.-W. Gurgel, H. Rohling, and T. Schlick, "HF Radar WERA Application for Ship Detection and Tracking," European Journal of Navigation, Vol. 7, No. 3, pp. 18-25, 2009.

[3] K.-W. Gurgel and T. Schlick, "Compatibility of FMCW Modulated HF Surface Wave Radars with Radio Services," International Radar Symposium IRS 2007, 2007, pp. 255-258.
[4] K.-W. Gurgel and T. Schlick, "Remarks on Signal Processing in HF Radars Using FMCW Modulation," International Radar Symposium IRS 2009, 2009, pp. 63-67.

[5] C. Iphar, A. Napoli, and C. Ray, "Detection of False AIS Messages for the Improvement of Maritime Situational Awareness," OCEANS 2015 MTS/IEEE Washington, 2015, pp. 1-7.

[6] H. Li, Y. He, and W. Wang, "Improving Ship Detection with Polarimetric SAR based on Convolution between Co-polarization Channels," Sensors, Vol. 9, No. 2, pp. 1221-1236, 2009.

[7] A.V. Dolgopolov, P.A. Kazantsev, and N.N. Bezuhliy, "Ship Detection in Image Obtained from the Unmanned Aerial Vehicle (UAV)," Indian Journal of Science and Technology, Vol. 9, No. 46, pp. 1-7, 2016.

[8] D.E. Barrick, "FM/CW Radar Signals and Digital Processing," National Oceanic and Atmospheric Administration, Tech. report, pp. 1-22, 1973.

[9] H.D. Griffiths, "New Ideas in FM Radar," Electronics and Communication Engineering Journal, Vol. 2, No. 5, p. 185-194, 1990.

[10] M. Ash, M. Ritchie, K. Chetty, and P.V. Brennan, "A New Multistatic FMCW Radar Architecture by Over-the-Air Deramping," IEEE Sensors Journal, Vol. 15, No. 12, pp. 7045-7053, 2015.

[11] A. Strobel, R. Eickhoff, A. Ziroff, and F. Ellinger, "Comparison of Pulse and FMCW based Radiolocation for Indoor Tracking Systems," 2010 Future Network and Mobile Summit, 2010, pp. 1-8.

[12] R.H. Khan and D. Mitchell, "Waveform Analysis for High-Frequency FMICW Radar," IEE Proceedings F (Radar and Signal Processing), Vol. 138, No. 5, pp. 411-419, 1991.

[13] K.-W. Gurgel, A. Dzvonkovskaya, T. Pohlmann, T. Schlick, and E. Gill, "Simulation and Detection of Tsunami Signatures in Ocean Surface Currents Measured by HF Radar," Ocean Dynamic, Vol. 61, No. 10, pp. 1495-1507, 2011.

[14] L. Sevgi, A. Ponsford, and H. Chan, "An Integrated Maritime Surveillance System Based on High-Frequency Surface-Wave Radars, Part 1: Theoritical Background and Numerical Simulations," IEEE Antennas and Propagation Magazine, Vol. 43, No. 4, pp. 28-43, 2001.

[15] S. Aulia, S. Tjondronegoro, and R. Kurnia, "Analisis Pengolahan Sinyal Radar Frequency Modulated Continuous Wave untuk Deteksi Target," Jurnal Nasional Teknik Elektro, Vol. 2, No. 2, pp. 51-64, 2013.

[16] S. Suleymanov, "Design and Implementation of an FMCW Radar Signal Processing Module for Automotive Applications," Master thesis, University of Twente, Enschede, Netherlands, 2016.

[17] C. Wolff (2019) "Frequency-Modulated Continuous-Wave Radar (FMCW Radar)," Radar Tutorial, [Online], http://www.radartutorial.eu/ 02.basics/Frequency\%20Modulated\%20Continuous\%20Wave\%20Rada r.en.html, access date: 29-Jul-2019.

[18] D. Utyansky, "Digital Signal Processing for Frequency Modulated Continuous Wave RADARs," Synopsys, Inc., California, pp. 1-11, 2018. 